\title{
Fundaciones frustradas y efímeras en la España Moderna. Memoria de los conventos franciscanos que no pudieron ser*
}

\author{
Ángela ATIENZA LÓPEZ \\ Universidad de La Rioja \\ angela.atienza@unirioja.es
}

Recibido: 27 de mayo de 2011

Aprobado: 7 de febrero de 2013

\section{RESUMEN}

Los rasgos más importantes de la expansión de las órdenes religiosas y la proliferación de conventos a lo largo de la Edad Moderna son asuntos hoy bien conocidos. Sin embargo, la historia de las fundaciones conventuales todavía tiene pendientes cuestiones que reclaman trabajo de investigación. Entre ellos está el estudio de aquellos conventos que se malograron, de las fundaciones efímeras y de los proyectos de fundación que quedaron frustrados y no llegaron a ver la luz. El objetivo de este trabajo es éste: identificar estas iniciativas fallidas o efímeras y analizar las razones de estas operaciones fracasadas, y todo ello centrado en la familia franciscana y tomando como fuentes principales las crónicas religiosas.

Palabras clave: Conventos, órdenes religiosas, fundaciones frustradas, crónicas religiosas, franciscanos.

\section{Failed and ephemeral foundations in Early Modern Spain. The memory of the frustrated Franciscans convents}

\begin{abstract}
The main features in the spread of religious orders and the proliferation of convents along the Early Modern Age are well known matters nowadays. Any way, research is still needed about some questions in this field. One of these open questions is the study of the failed convents, the ephemeral foundations and the founding projects that never happened. This is the aim of this paper: identifying these failed or ephemeral initiatives and analysing the reasons of their failures, focusing in the Franciscan family and taking the religious chronicles as the main source.
\end{abstract}

Key words: Convents, religious orders, failed foundations, religious chronicles, Franciscans.

\footnotetext{
* Este trabajo se realizó en el marco del Proyecto de Investigación de referencia HAR2008-06048-C03-02/ HIST y se ha revisado y terminado en el marco del Proyecto de Investigación HAR2011-28732-C03-02, financiado por el Ministerio de Economía y Competitividad, del que soy Investigadora Principal.
} 
Uno de los fenómenos más sobresalientes de la trayectoria histórica del clero regular y las órdenes religiosas en la España Moderna es su extraordinaria capacidad de expansión. La proliferación de conventos y de nuevas fundaciones fue verdaderamente impresionante y la inserción y la presencia social creciente de este sector del clero en aquellos siglos está hoy fuera de toda duda ${ }^{1}$. Una de las conclusiones bien asentadas en este terreno es el protagonismo y la gran presencia que en este proceso tuvieron las distintas ramas de la orden franciscana. Su propagación y el número de asentamientos que alcanzaron superó al de las otras familias de regulares.

La formación y configuración de esa España conventual franciscana, extensa y dilatada, tanto en su vertiente masculina como en la femenina, es en la actualidad bastante bien conocida en sus rasgos más sobresalientes.

Podemos decir que es precisa la definición que tenemos de lo que fue la geografía conventual franciscana a finales del Antiguo Régimen, ya culminado el proceso expansivo. También la investigación histórica ha dejado bastante bien perfilado el mundo de los promotores y fundadores de estos cenobios, igualmente contamos con suficiente información sobre las condiciones de institución de los nuevos conventos, las escrituras en las que se acordaron y se dejaron fijados los pactos fundacionales. Asimismo, conocemos cómo muchos de los procesos de fundación fueron complicados y se vieron acompañados de tensiones y conflictos de mayor o de menor calado y sabemos de las dificultades que formaron parte de las historias iniciales de muchas de las comunidades religiosas que fueron estableciéndose en territorio hispano ${ }^{2}$.

Sin embargo, la historia de las fundaciones franciscanas, igual que la del resto de las órdenes religiosas, todavía tiene pendiente asuntos que reclaman información, estudio y trabajo de investigación, entre ellos no es de menor trascendencia o de menor importancia el seguimiento de aquellos conventos que se malograron, de lo que podemos llamar fundaciones efímeras y también fundaciones frustradas. Fundaciones efimeras, las que tuvieron una vida muy corta, porque no todos las iniciativas fundacionales lograron llegar a consolidarse y a pervivir. Y fundaciones frustradas, porque hubo tentativas fundacionales que no superaron la fase del mero proyecto y

\footnotetext{
1 Es de referencia y consulta imprescindible, Martínez Ruiz, E. (dir.): El peso de la Iglesia. Cuatro siglos de Órdenes Religiosas en España, Madrid, Actas, 2004. Para el estudio de la expansión y proliferación conventual, Atienza LóPez, A.: Tiempos de conventos. Una historia social de las fundaciones en la España Moderna, Madrid, Marcial Pons, 2008.

2 La bibliografía disponible, de carácter general y particular sobre el mundo conventual franciscano de la España Moderna, es inmensa. Resulta imprescindible remitir a la consulta de la obra de CASTRO Y CASTRO, M. de: Bibliografia hispanofranciscana, Santiago de Compostela, s.n, 1994. Y citaré únicamente los trabajos más recientes que ofrecen un panorama más completo y las obras compilatorias de trabajos más específicos. Entre los primeros, García Oro, J.: Los franciscanos en España. Historia de un itinerario religioso, Santiago de Compostela, El Eco Franciscano, 2006. Y, AbAd Pérez, A. y SÁnchez Fuertes, C.: "La descalcez franciscana en España, Hispanoamerica y Extremo Oriente. Síntesis histórica, geográfica y bibliográfica", Archivo IberoAmericano, 234 (sept-dic, 1999), pp. 457-788. Entre los segundos, GrAÑA CID, Mª. M. (ed.): El franciscanismo en la Península Ibérica. Balance y perspectivas, Barcelona, GBG Editora, 2005. Igualmente, los distintos volúmenes ya publicados bajo el título El franciscanismo en Andalucía. Varios Cursos de Verano. Córdoba, Asociación Hispánica de Estudios Franciscanos, 1997 y ss. Por supuesto, una referencia indispensable para los estudiosos de la historia franciscana es la revista Archivo Ibero-Americano. Igualmente, es importante considerar la referencia de la reciente Historia de las diócesis españolas de la BAC que lleva ya un buen número de volúmenes publicados.
} 
porque tampoco todas las iniciativas fundacionales que se pusieron en marcha pudieron o llegaron a ver la luz 3 .

Ciertamente, es éste un terreno de investigación que no resulta fácil y que presenta dificultades y complicaciones en la medida en que se trata de buscar los rastros de lo que no se consiguió y de lo que no perduró. Las informaciones están diseminadas en múltiples lugares. Muchas veces noticias de estos proyectos han podido quedar aisladas en los archivos municipales, o en los archivos de las provincias religiosas, o en los archivos judiciales o de los Consejos que pudieron tener alguna actuación en esta materia cuando los intentos de fundación pasaron por algún litigio. En cualquier caso, las referencias son dispersas e inciertas, y si bien hay algunos trabajos puntuales al respecto ${ }^{4}$, lo cierto es que queda todavía mucho trabajo pendiente de investigación histórica.

Pero las crónicas franciscanas nos permiten ahondar en esta realidad ${ }^{5}$. En mi trabajo con estas fuentes cronísticas he ido pacientemente recuperando los datos y la información sobre estos conventos que no perduraron y sobre los proyectos fundacionales que se frustraron, en definitiva sobre lo que podemos considerar esa España franciscana que no pudo ser. La identificación de estos cenobios y estos intentos fundacionales y la aproximación a las razones de estas operaciones fracasadas a partir del estudio de varias crónicas de provincias ${ }^{6}$ constituyen los objetivos fundamentales que nos planteamos en este artículo.

No obstante, antes de avanzar, parece conveniente precisar que el análisis histórico en un tema de estas características tiene sus límites. Respecto a la cronología del fenómeno, podemos apuntar tendencias, pero no es posible ofrecer una sistematización cronológica que se pretenda válida, veraz y rigurosa. Presentamos los datos de

3 He planteado una introducción de carácter general a estas cuestiones, centrada más en el análisis de los fundadores que vieron frustradas sus expectativas, en AtiEnZA LóPEZ, A.: "Fundaciones y fundadores frustrados. La otra cara de la expansión conventual en la España Moderna”, en Soria MEsA, E. y DíAz RodrigúEz, A. J: Iglesia, poder y fortuna. Clero y movilidad social en la España Moderna, Granada, Comares, 2012.

$4 \mathrm{Si}$ bien aportaciones no se ciñen en exclusiva al mundo de los conventos franciscanos cabe citar los trabajos de Aranda Doncel, Juan: "Fundaciones conventuales masculinas en la diócesis de Córdoba durante el siglo XVII: los proyectos fallidos”, en Estudios en homenaje al profesor José Szmolka Clares, Granada, Universidad de Granada, 2005, pp. 187-199. Del mismo autor, "Un proyecto frustrado en la villa cordobesa de Palma del Río en el siglo XVII: la fundación de los mercedarios descalzos", Boletín de la Real Academia de Córdoba, 141 (2001), pp. 183-192. Gallardo Téllez, E.: "Fundaciones religiosas frustradas en VélezMálaga durante los siglos XVII y XVIII”, Isla de Arriarán, XVI (2000), pp. 55-67. Y, Cortés PeÑA, Antonio Luis: "Intentos de fundaciones religiosas en el reinado de Carlos III", en Cortés PeÑA, A. L. (ed.): Poder civil, iglesia y sociedad en la Edad Moderna, Granada, Universidad de Granada, 2006, pp. 399-412.

5 Sobre el amplísimo y rico mundo de la cronística de las órdenes religiosas, AtiEnZA LóPEz, A: "Las crónicas de las órdenes religiosas en la España Moderna. Construcciones culturales y militantes de época barroca”, en Atienza López, A. (ed.): Iglesia Memorable. Crónicas, historias, escritos... a mayor gloria. Siglos XVI-XVIII. Madrid, Sílex, 2012, pp. 27-52.

6 Iremos dando las referencias completas en cada momento, pero resumimos ahora las consultadas para este trabajo: Anónimo: Crónica de la provincia franciscana de Santiago; José de Santa Cruz: Provincia de San Miguel; Jacobo de Castro: Primera parte del Árbol Cronológico de la Provincia de Santiago; Juan de San Antonio: Franciscanos descalzos en Castilla la Vieja; Francisco Jesús María: Provincia de San Diego (descalzos); Alonso de Torres: Provincia de Granada; M. Garay: Compendio cronológico, provincia de Burgos; P. M. Ortega: Provincia de Cartagena; A. Panes: Provincia de San Juan Bautista (descalzos); V. Martínez Colomer: Provincia de Valencia; G. García Alcaraz: Provincia de San Pedro de Alcántara (descalzos) y J. de Santa María: Provincia de San José (descalzos). 
las fundaciones efímeras y frustradas de las que tenemos noticia, pero hay que ser consciente de que queda espacio de desconocimiento, y tampoco sabemos la entidad del mismo. Desconocimiento referido a otras fundaciones naufragadas de las que no se ofrece referencia alguna en las fuentes que manejamos, intentos fundacionales fracasados que los cronistas no recogieron (aunque sí pudieron dejar rastro en otro tipo de depósitos documentales) y desconocimiento también que afecta a los casos en los que esos cronistas no precisaban las fechas de aquellas operaciones malogradas $\mathrm{y}$, por lo tanto, ignoramos tal dato, como puede verse en el cuadro que presentamos al final del trabajo.

En definitiva, resulta muy compleja la investigación de lo que no llegó a ser, puesto que la información y las huellas que quedaron tienden a ser, lógicamente, escasas y, sobre todo, inciertas y hay que considerar que razonar sobre el conjunto del fenómeno en estas condiciones y sistematizar sus rasgos resultará siempre muy contingente y aventurado. Desde luego un análisis cronológico tropieza siempre con el escollo de la imprecisión, pero también profundizar en las causas de los fracasos fundacionales no resulta una tarea fácil.

Como veremos, no siempre los cronistas dieron cuenta explicativa puntual de lo que sucedió ni todos se explayan en el relato de los motivos por los que la institución de comunidades religiosas quedó paralizada o en las razones por las que otras tuvieron que ser cerradas, pero en cualquier caso consideramos que sacar a la luz los nombres de las localidades en las que se produjeron estas fundaciones fallidas facilitará a los historiadores la búsqueda de la documentación necesaria para completar estas historias, procesos que en ocasiones pudieron dejar huella no sólo en el ámbito de la propia orden religiosa, sino también en el seno de los municipios protagonistas, en el de los obispados o arzobispados correspondientes o bien en las instancias de gobierno que debían dar la correspondiente licencia fundacional o que intervinieron en posibles pleitos o demandas que los acompañaron. Todo ello, en fin, nos permitirá además ahondar en el análisis del proceso de expansión del clero regular en la España de los siglos modernos y aportar al conocimiento del mismo esta otra vertiente bastante menos conocida.

El proceso de constitución y de configuración de la España conventual en la Edad Moderna no tuvo un desarrollo histórico fácil. Los impulsos fundacionales fueron, sin duda, innumerables, pero en muchas ocasiones hacer realidad el establecimiento de una nueva comunidad religiosa y asegurar su pervivencia constituyó una operación plagada de complicaciones. Iremos viendo, a la luz de la información proporcionada por los textos cronísticos, cuál fue el abanico de dificultades que impidieron el nacimiento o la pervivencia de algunos conventos franciscanos.

Fundar un convento en la España Moderna constituía, entre otras muchas cosas, un acto institucional formal. La instalación de una nueva comunidad religiosa conllevaba diferentes exigencias y requisitos legales. La solicitud fundacional por parte de un particular o de una institución corporativa se hacía llegar al municipio que debía albegar el nuevo convento pues era preceptivo que éste concediera su autorización. También era preciso conseguir la licencia del obispo o del arzobispo correspondiente, la del Consejo de Castilla, o en su caso la del Consejo de Órdenes Militares si la localidad del establecimiento estaba situada en la demarcación competente a su jurisdic- 
ción, y el consentimiento del señor en aquellos enclaves dependientes de jurisdicción señorial... El acopio de permisos de distintas instancias formó parte de las historias fundacionales y estos requerimientos se podían convertir, como de hecho en ocasiones se convirtieron, en una fuente de complicaciones, en un poderoso escollo que había que superar y vencer Y no siempre se consiguió. En ocasiones las aspiraciones fundacionales encontraron en este terreno de las licencias y los consentimientos reglamentados su principal obstáculo.

En Honrubia (Cuenca), según explica el cronista fray Antonio Panes, fue la misma villa la que tomó hacia 1617 la iniciativa para conseguir una fundación de franciscanos descalzos y ofrecería a la orden y a su provincial el hacerse cargo de la fábrica del convento y de su sustento, siendo aceptada la propuesta. La villa pertenecía al marquesado de Villena, que otorgó su beneplácito. Por las mismas fechas también en la vecina localidad de Castillo de Garcimuñoz (Cuenca) se estaba pidiendo por parte de su concejo y del clero local el establecimiento de un convento de descalzos. Pero ninguna de las dos fundaciones llegaría a efectuarse. La explicación de Panes era ésta: "por dificultades que se ofrecieron y la principal no aver dado para ello licencia el Obispo de Cuenca" . Y es que, efectivamente, arzobispos y obispos tuvieron en la Edad Moderna una importante capacidad para regular y ordenar la presencia y la expansión de los regulares en sus respectivas diócesis, sobre todo desde que en Trento se declarara preceptiva la licencia episcopal para establecer cualquier nueva comunidad religiosa ${ }^{8}$.

La negativa episcopal también estaría detrás del fracaso de otros intentos de fundación conventual que afectó a la orden de los franciscanos descalzos algunas décadas más tarde. Sucedería en Huelma (Jaén), durante el provincialato de fray Alonso de Segura al frente de la provincia de San Pedro de Alcántara, hacia 1670. El relato de fray Ginés García Alcaraz permite ver además el cúmulo de diligencias en distintas instancias que implicaba una fundación conventual ya en estas fechas. También en este caso era la villa la que ya hacía tiempo había solicitado a los frailes descalzos la apertura de un convento en sus términos, en una ermita con la advocación de Nuestra Señora de la Fuensanta. El provincial tomaría la decisión de agilizar los trámites para ello. Conseguiría hacerse con el consentimiento del duque de Alburquerque, que ejercía allí su señorío, y “despachó luego sus Procuradores a los Reynos de Castilla, para que sacassen sus licencias, pues sin ellas, no se podia obtener la del Consejo Real" Efectivamente, ya en estos momentos avanzados del siglo XVII, los promotores e interesados en conseguir una fundación conventual estaban obligados a un importante despliegue de gestiones puesto que el Consejo exigía, antes de emitir su parecer y otorgar su licencia, que precediera el consentimiento de las ciudades con voto en

7 Panes, Fray A.: Chronica de la Provincia de San Juan Bautista de religiosos menores descalzos de la regular observancia de nuestro seraphico padre San Francisco, dedicada al Sacro, Supremo y Real Consejo de Aragón, Valencia, Gerónimo Vilagrasa, 1665, pp. 523-524 de la primera parte.

8 Sobre esta cuestión, Atienza López, op. cit. (nota 1), pp. 349 ss. Si bien, ciertamente, no parece que fueran muy numerosos los casos en los que la oposición de un obispo a la erección de un nuevo convento terminara frustrando definitivamente un intento fundacional, esto no quiere decir que no se produjeran.

9 García Alcaraz, Fray G.: Segunda Parte de las Chronicas de la Santa Provincia de San Pedro de Alcántara de religiosos menores descalzos de las más estrecha observancia de N.P.S. Francisco en los Reynos de Granada y Murcia, escrita por ..., Murcia, Nicolás Villagordo, y Alcaraz, 1761, pp. 82-83. 
Cortes para cada fundación. Al parecer en este caso se lograron todas las licencias exigidas, pero obtener la del obispo se convirtió en una muralla infranqueable y el convento de franciscanos descalzos en Huelma quedó en la historia de las aspiraciones malogradas, mucho más si consideramos que se reiterarían las gestiones un poco más tarde.

Efectivamente, el siguiente provincial, fray Salvador Aguayo -electo en 1672- volvería a dar impulso a los esfuerzos por conseguir esta fundación de Huelma y se encontró con el mismo parecer inquebrantable por parte del obispo ${ }^{10}$. En este mismo momento, las pretensiones de expansión de la provincia de san Pedro de Alcántara alcanzaban también a la localidad de Quesada (Jaén), donde al parecer también se había intentado anteriormente abrir una nueva comunidad de franciscanos descalzos, con las licencias de las ciudades de voto en Cortes, pero permanecía sin ejecutar. Ninguna de las acciones del provincial, ni las del agente que envió para lograr las licencias para ambos conventos dieron sus frutos. Ni el cardenal Aragón, arzobispo de Toledo, concedió licencia para fundar en Quesada, ni el obispo de Jaén, como hemos visto, la otorgó para Huelma. Ésta era la expresiva manifestación del cronista sobre el proceder y la actitud de los prelados: "Pero estos Príncipes se manifestaron tan inflexibles sobre el assumpto, que aun no dexaron el consuelo de la esperanza" ${ }^{11}$.

La negativa por parte de las autoridades episcopales a otorgar la preceptiva licencia estuvo, como vemos, en la base de la paralización de algunas iniciativas fundacionales. En otras ocasiones, parece que los problemas para consolidar y llevar a buen puerto el establecimiento de una nueva comunidad religiosa estuvo en el escaso o insuficiente compromiso por parte precisamente de alguna de las instancias que habrían solicitado la fundación conventual. Esto es lo que debió suceder en la villa de Aracena (Huelva) cuando el duque de Medina de las Torres pedía a la provincia de los franciscanos descalzos de San Diego que instituyeran un convento en los términos de aquella localidad en un sitio que llamaban de Arias Montano. Era el tiempo en el que ocupaba el cargo de provincial fray Francisco de la Madre de Dios, electo en 1656, y, por lo tanto, el duque de Medina de las Torres al que se refiere el cronista es el segundo de ese título, el famoso y poderoso don Ramiro Núñez de Guzmán que fue virrey de Nápoles y una de las figuras importantes y destacadas en el gobierno de Felipe IV. Así se explica la advertencia que introduce el cronista y que tiene un gran interés: las autoridades de la provincia no debían considerar esta fundación acomodada a sus necesidades ni parece que se ajustara a sus preferencias, pero sin embargo optaron por admitirla y dar su consentimiento. La calidad y entidad del promotor y el deseo de no contrariarle fue uno de los factores que pesaron en esta decisión ${ }^{12}$, lo

10 Ibidem, p. 87.

11 Ibidem, p. 87. En otra parte de la crónica, García Alcaraz vuelve a rememorar lo sucedido en estos dos intentos fundacionales y las gestiones que en Madrid hizo fray Melchor Cano, que había sido el agente enviado por el provincial para negociar las licencias. Su aseveración final es igualmente clara: "Y aunque se valió de los empeños más soberanos de la Corte, solo pudo conseguir la total repulsa de su pretensión”. Ibidem, p. 323.

12 El texto es el siguiente: “... y aunque respecto de el cuerpo de la Provincia, se consideraba esto muy extraviado, assi para el Provincial, como para los Subditos, no obstante, en atención a la veneracion de el sitio, y por condescender con el gusto de su Excelencia, dio la Provincia su consentimiento", Jesús MaríA, Fray F.: Primera parte de las Chronicas de la Provincia de San Diego en Andalucía de religiosos descalzos de N.P. San Francisco, escrita por... Sevilla, Convento de San Diego, 1724, p. 792. 
que nos ofrece una idea de cómo en ocasiones la geografía conventual de la España Moderna respondió a variables muy particulares y cómo no siempre el proceso siguió las pautas que pudieran marcar las órdenes ${ }^{13}$.

Lo cierto es que, pese a todo, la fundación del convento de Aracena no llegaría a ver la luz. Como avanzábamos arriba, todo indica que el duque de Medina de las Torres no debió responder convenientemente a los requerimientos de la operación fundacional una vez que le había sido admitida y las precisiones de la orden religiosa quedaron sin cumplirse, al menos esto es lo que pensamos que cabe interpretar de las crípticas palabras en torno a ello del cronista:

Representaronse a su Excelencia algunos preliminares, assi para el sustento de los Religiosos como para la fabrica. No sé la respuesta que dió; pero no se esconde mucho, quando vemos oy, que no se ha fundado, aviendo entonces la Provincia admitido. Sin duda, que las dos proposiciones, que hizo la Provincia, no se pudieron proveer por los atrasos, que entonces padecían ${ }^{14}$.

Por lo demás no hay que considerar que fuera éste un caso excepcional. Ciertamente, en la historia de otros conventos también es posible vislumbrar circunstancias de este tipo: fundadores y/o patronos que olvidaron pronto sus deberes y compromisos y abandonaron el respaldo que las comunidades religiosas precisaban para seguir adelante con un mínimo de holgura ${ }^{15}$. De hecho, como podremos ver más adelante, este tipo de situaciones estarían también detrás del abandono y desmantelamiento de comunidades religiosas ya establecidas.

Las décadas de los años sesentas y setentas del siglo XVII no debieron resultar fáciles para las aspiraciones de propagación de los franciscanos descalzos, aunque a estas alturas las dificultades para establecer nuevos conventos debían ser ya un hecho común para todas las órdenes. Algunas apreciaciones de los cronistas pueden ayudarnos a calibrar la magnitud del fenómeno que estamos estudiando y su especial incidencia a partir de estas décadas.

Así, el cronista de la provincia de San Juan Bautista, demarcación que se extendía por una buena parte del territorio valenciano, aseguraba que la provincia procuraba por esos años ampliarse tomando algunas fundaciones. Estamos en el provincialato de fray Diego de Oca, electo en 1663. Pero esta voluntad expansiva y las gestiones que se deducen no tuvieron los resultados esperados. El fraile asegura que sólo tuvo efecto la fundación de un convento, el de San Antonio de Padua en la villa de Pego que se produciría en $1664^{16}$. Todo demuestra que el impulso fundador de la orden se mantenía todavía vivo, pero que se estaba topando con bastantes más complicaciones y escollos que antes, que efectivamente debió haber ofrecimientos de fundación que llegaban a las autoridades provinciales y que tampoco pudieron sustanciarse, si bien en este caso no detalla el nombre las villas de los que procedían.

13 Atienza López, A.: "Nuevas consideraciones sobre la geografía y la presencia conventual en la España Moderna. Otras facetas más allá de la concentración urbana”, Hispania Sacra, 123 (2009), pp. 51-75.

14 Jesús MARÍA, op. cit. (nota 11).

15 Algunos casos pueden verse en Atienza LóPez, op. cit. (nota 1).

16 PANES, op. cit. (nota 7), pp. 1056-1057 de la segunda parte. 
Sí es más explícito fray Juan de San Antonio en su crónica de la provincia de San Pablo "en Castilla la Vieja". En su texto quedan identificadas las poblaciones en las que hubo expectativas e intentos de establecer una fundación pero quedaron frustrados, aunque por el contrario no se nos ofrece ningún dato que nos permita acercarnos a la cronología de estos episodios. Su información, de cualquier modo, tiene interés por dos razones. En primer lugar porque permite aproximarnos a una estimación de la entidad del fenómeno de intentos fundacionales truncados. Es posible constatar y poner de manifiesto que la entidad numérica de estas fundaciones malogradas respecto a lo que era la realidad y la magnitud conventual de la provincia es bastante notable. Fray Juan confirmaba que en el tiempo en el que escribía su crónica (la fecha de impresión es 1728) la provincia de San Pablo contaba con veintiséis conventos repartidos en ocho ciudades y diez y ocho villas. Las fundaciones que no habían podido salir adelante sumaban más de catorce. Eran éstas: Ciudad-Rodrigo, Oviedo, Astorga, Burgos, Rioseco, Pedraza, Fuente la Peña, La Puebla, Roa, Fermoselle ${ }^{17}$, cuatro villas del Bierzo, y añade además que también hubo algunas en "otras poblaciones no vulgares" que ya no detalla. Y, en segundo lugar, el testimonio de nuestro cronista también es especialmente valioso porque apuntaba hacia las razones de todos estos fracasos y de todas estas iniciativas arruinadas. Sus explicaciones quedaba resumidas en estas palabras:

Las fundaciones, que por las oposiciones tan continuas, como inevitables en semejantes lances, se han quedado en la idea de muchos nobles y devotos corazones que con vivas ansias las solicitaban, lo dixeran, si yo callara ${ }^{18}$.

"Oposiciones tan continuas e inevitables...". Ésta era la realidad que dibujaba el cronista franciscano y que marcó la historia de tantas y tantas fundaciones de conventos en la España Moderna. Naturalmente, sabemos bien que muchas operaciones para erigir un nuevo convento pudieron vencer estas contrariedades, pero también podemos empezar a valorar que hubo otras muchas que se encontraron con muros que resultó imposible vencer. Hasta tal punto alcanzaba la envergadura de los obstáculos y de las manifestaciones de oposición, y hasta tal nivel llegó la percepción de todas estas dificultades y la consideración de las contrariedades que el mismo cronista fray Juan de San Antonio llegaría a estimar que los conventos que efectivamente pudieron fundarse eran "los conventos del milagro". La afirmación completa de fray Juan era la siguiente:

17 De las poblaciones citadas es ésta de Fermoselle (Zamora) la única en la que los franciscanos descalzos lograrían finalmente establecer un convento, pero ya entrado el siglo XVIII. La referencia a este convento propio de la provincia de San Pablo, en Abad Pérez, A. y SÁnchez Fuertes, C.: "La descalcez franciscana en España, Hispanoamerica y Extremo Oriente. Síntesis histórica, geográfica y bibliográfica”, Archivo Ibero-Americano, 234 (sept-dic, 1999), pp. 457-788. La mención concreta en p. 554, en la que se indica que Fermoselle comenzaría siendo un simple hospicio, y que posteriormente sería elevado a la categoría de convento.

18 San Antonio, Fray J. de: Franciscos descalzos en Castilla la Vieja. Chronica de la Santa Provincia de San Pablo de las más estrecha regular observancia de N.P.S. Francisco formada... por el Menor Fr. Juan de San Antonio, Salamanca, Imp. de la Santa Cruz, 1728, p. 85. 
Lo indubitable es, que todos nuestros Conventos son sin exageración los Conventos del Milagro; porque solo con maravillas del Cielo se abrieron sus zanjas en la tierra, como dirá para gloria de Dios, quando haga de cada uno la memoria que debo ${ }^{19}$.

Una definición ésta que naturalmente hay que entender en el marco de aquellas mentalidades cargadas de providencialismo, pero que resulta tremendamente expresiva: debía parecer en efecto portentoso y producto de milagro el que se consiguiera el establecimiento de algunos conventos.

Algunas de estas discordias y manifestaciones de oposición ya las hemos visto. Y también es perfectamente conocido cómo en muchas ocasiones fueron las otras órdenes religiosas ya establecidas en la localidad o en sus proximidades las que se levantaron contra la apertura de una nueva comunidad religiosa. Esto es lo que sabemos que sucedería en la malograda fundación de los franciscanos descalzos en Oviedo. Aquí sí sabemos que cuarenta y cuatro vecinos liderados por Diego Valdés Miranda y Bartolomé García Escaxadillo, que además recibirían el apoyo de personas como el marqués de Valdecarzana, solicitaron en 1650 al Ayuntamiento que permitiera la fundación de un convento de franciscanos descalzos. Fueron las restantes comunidades de la población las que se opusieron y consiguieron frenar el intento ${ }^{20}$.

En otras ocasiones fueron las mismas órdenes religiosas las que se autoimpusieron un cierto control y contención en sus deseos fundacionales y en sus apetencias de expansión ante la situación de excesiva saturación conventual de algunas poblaciones y/o ante las seguras polémicas que se iban a desatar y tomaron la decisión de no avanzar sobre perspectivas fundacionales que se le abrían. Es interesante en este sentido el ejemplo de lo acontecido en Tobarra (Albacete), que cabe explicar en cierta medida con estos parámetros. A principios de 1604, el obispo de Cartagena firmaba una provisión por la que concedía su licencia y daba respaldo a la provincia de San Juan Bautista de los franciscanos descalzos para que pudieran edificar tres conventos: uno en Cartagena, otro en Lorca (Murcia) y otro en la villa de Tobarra (Albacete). En sus justificaciones, el prelado aducía, entre otras consideraciones, las instancias que le hacían llegar los pueblos y moradores para conseguir estas fundaciones ${ }^{21}$. Es

\footnotetext{
19 Ibidem, p. 85.

20 La información la aporta Alonso Álvarez, R.: La arquitectura franciscana en Asturias. De la fundación a la desamortización, Oviedo, Real Instituto de Estudios Asturianos, 1995, p. 135.

21 Es el cronista Panes el que incluso transcribe literal y completamente el escrito del obispo don Alonso Coloma: "Aviendo visto por experiencia, y tenido larga noticia en la visita que voy haziendo en este mi Obispado de Cartagena, del mucho provecho, que hazen en todo él; y santa edificación, y exemplo, que dan los Padres Descalços de San Francisco de la Provincia de San Juan Bautista, en los lugares, donde tienen casas, y Conventos, assi con su dotrina en las predicaciones, y confessiones como con la mucha, y grande prudencia en componer los animos, y pacificar las voluntades de los vezinos, de que yo he tenido, y tengo grandes experiencias en los casos particulares. Deeseando que tan santa obra vaya muy adelante, y estos Padres hagan el mismo provecho en todos los lugares desta mi Diócesis, movido por la devocion que les tengo y juntamente por la instancia q me hazen los pueblos y moradores dellos. Por la presente doy y concedo licencia, y facultad por esta mi provision escrita de mi mano y firmada de mi nombre al Padre Provincial de la dicha Provincia de los Descalços de San Juan Bautista, para que pueda edificar tres Conventos, en la Ciudad de Cartagena, Ciudad de Lorca, y Villa de Tobarra deste mi Obispado, precediendo para ello licencia y beneplacito de Su Majestad, y de los Señores que residen en su muy alto consejo. Y certifico en toda conciencia, y verdad, que me consta ser estas fundaciones de grande servicio de N. Señor, y utilidad publica. Fecha en Murcia a primero de Febrero de este año de 1604. El Obispo de Cartagena". PANES, op. cit. (nota 7), pp. 412-413 de la primera parte.
} 
importante tenerlo en cuenta porque una buena parte de la expansión conventual de la España Moderna tiene tras de sí el gran apoyo social y entusiasmo de las poblaciones que lo alentaron, sin que esto signifique ninguna contradicción con el hecho de que tantas fundaciones encontraran a su paso fuertes oposiciones y contrariedades, normalmente más delimitadas desde el punto de vista social y/o corporativo, aunque, eso sí, también con mayor capacidad de influencia y con más recursos para conseguir sus objetivos.

En esas fechas de 1604 el aval del obispo significaba adelantar bastantes pasos en la consecución de una fundación. Todavía no se habían aprobado las famosas condiciones de millones que vendrían a entorpecer y complicar bastante el avance en la proliferación de nuevos establecimientos conventuales ${ }^{22}$. Sabemos además que el mismo obispo se implicó todavía más personalmente en la fundación del cenobio de Cartagena, escribiendo un informe para el monarca y su Consejo ${ }^{23}$. Sin embargo, el resultado efectivo de las tres licencias fue en aquel momento poco eficaz. Así lo relataba otro cronista, García Alcaraz, que también daba cuenta de la triple licencia otorgada por el ordinario:

Consiguiese entonces la Fundacion de Cartagena, impossibilitandose la de Tobarra, por haberla prevenido los Padres Observantes de la Santa Provincia de Cartagena, tomando Convento en esta Poblacion; que no siendo capaz de otro, se omitió el solicitarlo. La Fundacion de Lorca quedó suspensa por los muchos, y graves litigios, que especialmente padece semejante expedicion en Poblaciones, donde ya viven otras Comunidades ${ }^{24}$.

Efectivamente, Tobarra pasó a formar parte de la nómina de fundaciones frustradas de los franciscanos descalzos. Parece que se adelantaron los franciscanos observantes abriendo su convento y la provincia descalza decidió contener entonces sus aspiraciones considerando que debía ser ya excesivo. Esto es lo que indica el cronista, sin embargo una indagación más precisa nos lleva a plantear que fue posible que los mismos descalzos debieron posponer algo esta fundación. Tenían la licencia en 1604 y en Cartagena fundaron en 1606. Sin embargo la entrada de los observantes en Tobarra no se produjo hasta 1609 , estableciéndose primero en calidad de hospicio, y pasando posteriormente a la consideración de convento ${ }^{25}$; por lo tanto, hubo ahí un tramo de años en los que no parece que los descalzos dieran empuje a las gestiones, quizás porque prefirieron dar preferencia a las fundaciones en las dos ciudades: Cartagena y Lorca.

También Lorca quedaría en aquel momento en esa misma nómina de fracasos para los franciscanos descalzos. El cronista remite a los litigios que se presentaron y mencio-

22 Sobre la sensibilidad manifestada por las Cortes de Castilla ante la proliferación de religiosos y conventos y el detalle de la famosa condición de millones, puede verse, AtienZA LóPez, op. cit. (nota 1), pp. 64-66.

23 Panes, op. cit. (nota 7).

24 García Alcaraz, op. cit. (nota 9), p. 365.

25 Los datos sobre la fundación de los franciscanos observantes en la ciudad de Cartagena proceden de Ortega, P. M.: Crónica de la Provincia Franciscana de Cartagena. Parte Primera. (Edición facsímil de la impresa en Murcia en 1740). Introducción de J. Meseguer Fernández. Índices y coordinación general de la edición de V. Sánchez Gil, Madrid, Editorial Cisneros, 1980, pp. 556-558. 
na a las otras comunidades religiosas asentadas. Pero si bien Tobarra se convirtió en una frustración permanente, Lorca tendría otra oportunidad a finales de la centuria, cuando los descalzos lograron entrar en 1688, fundando primero como hospicio y ascendiendo a convento después ${ }^{26}$.

Las controversias generadas por los conventos y las órdenes religiosas ya establecidas en cada localidad fueron ciertamente una constante reiterada en las historias fundacionales. La rivalidad entre las órdenes es bien conocida y explicable en aquel mundo de Antiguo Régimen. Sin embargo, también en algún caso las querellas internas y las disputas entre miembros de la misma orden religiosa hicieron acto de presencia y terminaron por malograr algún que otro intento fundacional. Los franciscanos observantes no lograrían asentarse de forma definidita en Elche por este motivo. El caso es interesante por las razones de su frustración, que no debieron ser muy habituales, pero tampoco inconcebibles.

En Elche, hacia 1520 coincidirían las apetencias de la provincia franciscana de Aragón y las aspiraciones de la recién instituida provincia franciscana de Cartagena. Hacía muy poco que se había fundado en la localidad un convento de franciscanas clarisas, en 1517, y cuando se creó la demarcación de Cartagena, ésta pretendió absorber la obediencia de la mencionada comunidad de religiosas, algo que también reclamaría la provincia de Aragón, alegando que el cenobio estaba fundado en los límites de la Corona de Aragón. Este contencioso se enredaría con el que ahora nos interesa: la villa de Elche había pedido una fundación de convento de franciscanos observantes y, como sucedió en otras ocasiones, la población se dividió y repartió sus preferencias. Si el litigio provocó la polarización y la contienda entre la población o, si por el contrario, fue un estado de tensiones y enfrentamientos preexistentes lo que causó la disputa es siempre algo difícil de determinar, lo cierto es que hacia 1520 en Elche una parte de la población quería que la fundación del convento la hiciera la provincia de Cartagena mientras otra manifestó su inclinación hacia la provincia de Aragón. Cuenta el cronista que, en consecuencia, debieron llegar a la localidad frailes de ambas provincias, con lo que es fácil imaginar que el ambiente y el contencioso se enrarecieron todavía más y las posturas se endurecieron. El final llegaría en 1521 y desde las más altas instancias de la orden seráfica. En ese año se celebraba en Carpi, en la Lombardía italiana, el Capítulo general de la religión y allí se abordaría el asunto que enconaba la relación entre los frailes de ambas provincias españolas, que pudieron exponer sus razones y argumentos, y la resolución acabaría por detener las ambiciones de las dos partes: ninguna de las dos provincias fundaría en Elche y ambas debían abandonar la prosecución de su empeño. La dependencia del convento de clarisas, por lo demás, se adjudicaría a la provincia de Cartagena ${ }^{27}$. Este intento fundacional desafortunado sería definitivo. Nunca después

26 García Alcaraz, Fray G.: Segunda Parte de las Chronicas de la Santa Provincia de San Pedro de Alcántara de religiosos menores descalzos... (nota 9), pp. 364-369. Sobre el patronato de este convento, puede verse también Segado Bravo, P.: "Patronazgo de la familia Pérez de Meca en los siglos XVII-XVIII. El convento de San Diego de Lorca", en Actas del VII Congreso Español de Historia del Arte. Mesa I (Patronos, promotores, mecenas y clientes). Murcia, Universidad de Murcia, 1992, pp. 413-420.

27 Ortega, op. cit. (nota 25), p. 143. 
llegaron a fundar los franciscanos observantes en la localidad de Elche; sí lo hicieron en cambio los franciscanos descalzos unas décadas más tarde ${ }^{28}$.

Junto a estas fundaciones conventuales frustradas que hemos repasado, también hay que incorporar otras que igualmente nombran los cronistas aunque no se extienden en detalles al respecto. Así, J. de Castro mencionará algunas en el breve balance en el que deja constancia de que, además de fundaciones que no se admitieron, también en la provincia de Santiago de los franciscanos observantes hubo conventos que no subsistieron y fueron abandonados. Estas eran sus palabras:

Por este motivo entiendo no subsisten muchas de las que los Padres Pasqualinos multiplicaron en breve tiempo, y tuvo la Provincia por providencia no conservarlas; la misma razón tuvo para dexar otras, que me persuado se erigieron en el principio de la Observancia; y finalmente esta sería la unica para no admitir las que se nuevo se le ofrecieron, principalmente la que pidió en Bembibre el Excelentisimo Señor Conde de Alva de Aliste; otra en Mondoñedo, año de mil y seiscientos, para Recoletos, a instancias del señor Obispo; otra en Gijón, para Recoletos, que deseó aquella devota Villa, año de mil seiscientos y uno; dos en Salvatierra, y Puente-Areas, siendo General el Reverendisimo Padre Fray Francisco de $\mathrm{Sosa}^{29}$.

El relato que nos ha dejado J. de Castro no sólo aporta la recuperación para la historia de los nombres de las localidades en las que quedaron paralizados los intentos de asentar conventos franciscanos, sino que también nos sitúa ante un escenario explicativo diferente que ofrece un gran interés.

Como se ve en el texto citado, la política de la orden constituye el centro de la argumentación del cronista. No se trata de fundaciones abandonadas o malogradas por incapacidad y dificultades para conseguir las licencias necesarias, tampoco se trató de que se vieran envueltas en procesos de oposición a las mismas que resultaron insalvables... Se trataba de conventos que las autoridades de la provincia consideraron que no era provechoso conservar o bien de propuestas de fundación de cenobios que estas mismas autoridades estimaron que no convenía aceptar y quedaron en meros intentos coartados. Veremos más adelante algunos casos más en los que esta perspectiva que remite a decisiones tomadas por las jerarquías de las órdenes religiosas forma parte importante de la explicación de las renuncias a mantener algunos de los conventos.

Se trata, en nuestra opinión, de una faceta y de una dimensión del proceso de expansión de las órdenes religiosas que no ha sido normalmente considerada. Ciertamente,

28 Refiere la fundación descalza, SANTA María, Fray J. de: Chronica de la Provincia de San Joseph de los Descalços de la Orden de los Menores de N. Seraphico Padre San Francisco y de las Provincias y Custodias Descalças, que della han salido y son sus hijas, Madrid, Imprenta Real, 1625, p. 61.

29 Y aún añade: "Las que se sabe tuvo antes esta Provincia, aunque no passaron de Eremitorios, fueron el de Santa cruz en Valdeorras, el del Espiritu Santo cerca de Tuy, el de Santa María de Villavieja, otro en Puerto Marín. Finalmente en Salamanca tuvo esta Provinica a su direccion y enseñança el Colegio de la Concepcion, en que avia Religiosos, Rector, y Lectores de aquel Colegio para Colegiales Seglares; pero siendo Provincial el M. Reverendo Padre Fray Joseph Vazquez, faltaron las rentas de la fundacion, las que entiendo están ya mas bien puestas; y será lastima, que cuando se pueda, no se resucite aquella pia memoria, que es de tanto credito a la Escuela, y utilidad de la enseñanza publica". CAstro, J. de: Primera parte de el Arbol cronológico de la Provincia de Santiago, Reproducción fotolítica de la edición de 1722, Madrid, Editorial Cisneros, 1976, pp. 260-261. 
los estudiosos de este tema hemos puesto nuestro acento habitualmente en la pulsión fundacional de todas las familias religiosas, en el extraordinario empeño que manifestaron por multiplicar su presencia, especialmente visible entre las nuevas órdenes y las reformadas. Sin embargo, también es preciso incorporar en el examen de este proceso esta otra dimensión que remite a una imagen de unas órdenes religiosas más contenidas, que en muchos casos estudiaron con cuidado los pasos fundacionales que daban, actitudes entonces más reflexivas en materia fundacional de lo que en principio cabía mantener. No pensamos que ambas facetas sean contradictorias ni incompatibles. Naturalmente, parece conveniente un encuadre más reflexivo y explicativo y, en esta medida, procede afinar mucho más nuestro análisis y pienso que debemos hacerlo en dos direcciones: por un lado, distinguiendo entre las órdenes religiosas y, por otro lado, distinguiendo también los "tiempos" y los espacios. No fue el mismo el comportamiento durante la Edad Moderna de las órdenes antiguas, de fundación medieval, que el de las nuevas y reformadas, tampoco fue equivalente la dinámica y la actitud de las órdenes más vinculadas a la práctica de la mendicidad respecto a la que manifestaron las menos dependientes de la actividad limosnera. Tampoco fue lo mismo para la progresión fundacional el siglo XVI que el XVII, sobre todo ya en su segunda mitad, o el XVIII. Igualmente las perspectivas y el horizonte de posibilidades para las órdenes variaban en función de los enclaves en los que se estaban ofreciendo las fundaciones, más o menos poblados, más o menos urbanizados, más o menos densos en otras presencias conventuales, más o menos ricos...

Las consideraciones y explicaciones que ofrecía J. de Castro, que publicaba su trabajo en 1722, a principios del siglo XVIII, que se refería a los franciscanos observantes y que remitía a la provincia de Santiago -Galicia y la zona más oriental de Castilla: tierras de León, Zamora y Salamanca- eran las siguientes:

...consta aver tenido otros Conventos, Eremitorios, y Fundaciones que oy no subsisten, y otras que arreglandose al Santo Concilio de Trento, y constituciones generales, no admitió en perjuizio de los ya fundados, deseando ser menos gravosos a los Pueblos, en cuyas liberales, y piadosas limosnas, nos señaló nuestro Serafico Padre, la mesa de la Providencia de el Señor, pidiendo de puerta en puerta con que sustentarnos, sin empacho de ser pobres Evangelicos. Esta maxima observada de nuestros Padres antiguos, no multiplicando Conventos, y deseando menos de los que se ofrecían; verdaderamente se funda en un debido amor a una puntual regularidad mas observable, y mas facil en Conventos, cuya gravedad mantiene el orden preciso en todas las funciones de una Comunidad numerosa, o por lo menos mediana, que en los que a cada accidente se ven precisados a menos autoridad, y assistencia en un todo: por esso no magnificaban aquellos Padres con razon, por multitud de Conventos la alegria de la Observancia de nuestro Instituto, sino que por la mas exacta regularidad regulavan los Conventos ${ }^{30}$.

Y pasamos ahora a otra de las facetas que presentó este mundo de las fundaciones fracasadas en el seno del franciscanismo. Cabría hablar con más propiedad de fundaciones conventuales efimeras, haciendo referencia con este calificativo a aquellos conventos que sí llegaron a establecerse, que lograron ser una realidad, que tuvieron

30 Ibidem, p. 260. 
su toma de posesión, pero que no consiguieron subsistir y, por diversas razones, fueron abandonados al cabo de un tiempo. En nuestra opinión estas fundaciones pueden igualmente asimilarse a fundaciones frustradas. Es cierto que frente a las que hemos visto hasta aquí -fundaciones que nunca llegaron a ver la luz-, éstas otras sí se realizaron, pero no lograron sostenerse, no se conservaron..., y en un contexto en el que hubo tantos establecimientos de regulares que pervivieron y llegaron hasta el Antiguo Régimen, estos otros casos ciertamente pueden ser considerados fallidos y malogrados y, en este sentido, como decimos, constituyeron fundaciones frustradas. De estas comunidades de duración efímera nos ocuparemos ahora.

Algunos de los cenobios compartieron las razones de su temprano fin en la versión de los cronistas que nos informan de ello. La insalubridad del lugar en el que se había instalado el convento constituye una de las explicaciones que se repitieron en varios casos. Es lo que se arguye cuando se daba cuenta del abandono del convento de Sollana (Valencia) por parte de los franciscanos descalzos. Se trataba de una comunidad constituida en torno a 1562 y que la Provincia determinó desamparar totalmente hacia 1603

...por la poca salud que en ella se experimentaba, respecto de estar todo aquel distrito hecho un pantano con los almarjales de arrozes, que en grande abundancia se siembra, $\mathrm{y}$ inficionarse dellos el ayre. Y aunque se hizieron muchas experiencias, para ver si con algun medio podían remediarse tantas enfermedades, ninguo dellos aprovechó, y assí fue precisso dexarle... ${ }^{31}$.

Duración muchísimo más breve tuvieron los cenobios que se habían establecido en Almenara (Castellón) y en Castalla (Alicante), también de franciscanos descalzos. En la primera localidad los frailes tomarían posesión en 1574 y un año más tarde fundarían en Castalla. Los dos conventos se abandonaron en 1585, y en los dos casos la insalubridad del entorno era la explicación dada. Pero en este caso, el cronista va un poco más allá y nos ofrece una perspectiva de carácter más general y más ajustada:

El gran deseo que el Custodio tenía de ampliar la Custodia; y el devoto afecto, y aceptacion, que en qualquier parte que quería fundar, hallava, fue causa de que tomase algunos Conventos en lugares, y sitios poco sanos, y comodos para nuestro estilo de vida ${ }^{32}$.

Ciertamente constituyó ésta una realidad bastante extendida en el proceso de expansión del clero regular en la España del Antiguo Régimen. Las aspiraciones de las custodias a alcanzar la entidad de provincia y las de ambas a extenderse y consolidarse llevaron en muchas ocasiones a aceptar y ejecutar fundaciones apresuradas, a establecer conventos de forma poco adecuada. Los afanes de las órdenes religiosas por multiplicar su presencia se ligaron bien entonces con los deseos de tantas poblaciones por tener cerca un convento y así se aceptaron reclamaciones fundacionales sin demasiadas exigencias. Los mismos cronistas fueron conscientes de ello y así lo manifestaron, y

\footnotetext{
31 PANES, op. cit. (nota 7), p. 36 de la primera parte.

32 Ibidem, p. 95 de la primera parte.
} 
esto no sólo sucedió en las órdenes del mundo franciscano, sino también en otras familias religiosas ${ }^{33}$.

Un buena muestra de cómo esta necesidad de conventos, esta naturaleza expansiva de las órdenes religiosas empujaba el despliegue fundacional muchas veces de forma algo precipitada lo aporta el caso de Fonz (Huesca) ${ }^{34}$, un caso que presenta además varios intereses añadidos. En primer lugar, porque no se trata sólo de una fundación efímera más, sino que nos acerca también a otro fenómeno de fundación frustrada de más alcance: la de la posibilidad de establecer una nueva provincia del franciscanismo descalzo en territorios del reino de Aragón. Y en segundo lugar, porque nos permite aproximarnos, en este esfuerzo explicativo que intentamos con las información de la que disponemos, a otra de las razones que marcaron también los abandonos de cenobios por parte de las órdenes religiosas.

En este caso fue el obispo de Lérida el que se dirigiría por escrito al provincial de los franciscanos descalzos de San Juan Bautista pidiendo que fundaran en el reino de Aragón, concretamente en Fonz, un convento y ofreciendo que daría otros tres o cuatro de su mismo obispado porque deseaba que se estableciera en aquel reino otra nueva provincia ${ }^{35}$. La proposición del prelado lógicamente debió significar una noticia de importancia extraordinaria para las autoridades de la provincia. Se trataba nada más y nada menos que de la posibilidad de empujar la expansión hacia el norte y de iniciar la penetración en tierras aragonesas ${ }^{36}$. No era, por lo tanto, un asunto carente de trascendencia, y la fundación en Fonz se llevó a efecto en 1638. Era, como decimos, la primera fundación de los franciscanos descalzos en el reino de Aragón. Pero las perspectivas de proseguir y dar alas a la presencia de los franciscanos descalzos en estas tierras también resultaron fallidas. La versión del cronista es la siguiente:

Estas finezas, y demostraciones del señor Obispo, y el aver ofrecido otras fundaciones en aquel Obispado, que se entendió tendrían efecto, fue motivo de tomar esta casa, mas luego mostró la experiencia el engaño que avia avido, porque en los lugares mas principales de aquel contorno, como son Barbastro, Monçó, Banavarre, Tamarit, Graus, y Fraga, aun los Conventos que avia, no podian passar, con ser las Comunidades cortissimas, que muchas dellas no llegavan a seis Religiosos, y para una limosna de pan, avian de correr veinte leguas; pues desde Fons hasta la Provincia solo avia Alcañiz y Caspe, que fuessen lugares de algun posible, y estos estavan cargados tambié de Conventos. Los otros, que se propusieron para fundar, eran tan cortos, y disconvenientes, q el entrar en ellos fuera abrir puerta a gran distracció. Y assi en el capitulo venidero se determinó dexar el Convento de Fons, y antes se a dexado el de Almenara, y verdaderamente los naturales dezian bien que aquella tierra no es a proposito para quien, como nosotros, ha de vivir de puras limosnas ${ }^{37}$.

33 Atienza LóPez, op. cit. (nota 1), pp. 442 y ss.

34 El cronista Panes se refiere a "Fons", del reino de Aragón y obispado de Lérida. Se trata de la localidad de Fonz, situada en territorio de Huesca. PAnes, op. cit. (nota 7), p. 204 de la segunda parte.

35 Panes apunta que el obispo de Lérida lo había sido antes de Orihuela, donde habría podido hacerse "muy devoto de la Provincia", lo que explicaría sus intenciones de poder desarrollar otra en estas tierras de Aragón. Ibidem, p. 205.

36 Todavía no se había fundado en Alcorisa (Teruel), que sería lo más al norte que, en esta parte oriental de la Península, llegarían a fijar su residencia permanente los franciscanos descalzos.

37 PANes, op. cit. (nota 7), pp. 205-206 de la segunda parte. 
Como vemos, la escasez y la insuficiencia de limosnas en aquellas tierras son los motivos que se argüían para explicar no sólo el cierre del convento de Fonz sino también la contención fundacional que afectaría a las otras propuestas fundacionales, aunque no se da el detalle de las localidades implicadas. En definitiva, la incapacidad para asegurar la subsistencia de los frailes sería la razón que llevó a las autoridades provinciales a abandonar estas tierras aragonesas. Tiempos de crisis, y espacios en crisis. Lógicamente, también hay que tener en cuenta que la distancia desde Fonz, en Huesca, hasta los conventos más próximos, que eran los de Vinaroz o La Jana, en tierras castellonenses, era una distancia considerable y que, por tanto, asegurar la integración y la atención de aquel convento oscense en las estructuras de la provincia de San Juan Bautista debía suponer un gran esfuerzo.

La limitación de las limosnas y las dificultades para asegurar el sustento de los frailes sería un elemento que estaría también detrás de la duración efímera de otros conventos y que llevaría a las autoridades provinciales respectivas a tomar la decisión de no mantener la presencia en determinadas localidades. En Biar, un municipio situado en el interior de la tierra alicantina, la provincia de Valencia de los franciscanos observantes habría aceptado en 1572 establecer el convento que les pedía la villa. Pero en 1588 la comunidad era desmantelada: "...la extrema necesidad que padecían sus Frayles por la escasez de limosnas" es el motivo expuesto por el cronista ${ }^{38}$. Algunos años menos todavía duraría la fundación de Lliria (Valencia), igualmente de los franciscanos observantes. Los frailes se establecerían en 1562 y se marcharían para siempre en $1571^{39}$.

Unos años más tarde sería la localidad de San Mateo (Castellón) la que pasaría por una experiencia brevísima de establecimiento conventual en sus términos. En 1582 fundaban convento los franciscanos descalzos y en sólo dos años se desmantelaba el cenobio. La explicación que pudo ofrecer el cronista Panes es lacónica, y a él mismo le parece insuficiente: La fundación, según asegura:

se dejó passados dos años dize que por no hallarse agua para la huerta en el sitio que estaba: parezeme que pudiendo remediarse esto, eligiendo otro puesto, devió sin duda aver otras causas ${ }^{40}$.

$\mathrm{Y}$, efectivamente, algunas otras causas estuvieron detrás del fulgurante desamparo del convento de San Mateo. Es el cronista de la provincia de San José, fray Juan de Santa María quien nos aporta alguna mención más, y quien además nos pone en contacto con otras fundaciones perecederas que se produjeron entre los franciscanos descalzos. Señalará los abandonos que se produjeron "en este tiempo" -estamos en los años ochentas del siglo XVI-, en Almenara y en Castalla, según ya hemos visto, asegurará

38 Martínez Colomer, Fray V.: Historia de la Provincia de Valencia de la Regular Observancia de San Francisco. Tomo Primero. Cito por el manuscrito conservado en AHN, Consejos, Leg. 50840, n 646, p. 194. Si bien, de esta crónica hay publicación y reproducción por la editorial Cisneros de la edición del año 1803 . Es edición preparada por Benjamín Agulló. Madrid, 1982.

39 "Su clima entonces nada saludable, la escasez de limosnas que se recogían, y otras influencias poco favorables, iban deteriorando cada día mas la salud de los Frayles y haciendoles inhabiles para el cumplimiento de sus obligaciones..." y llevando a las autoridades a cerrar definitivamente el convento. Ibidem, AHN, Consejos, Leg. 50840, no 646. P. 189. La referencia a la fundación y su fecha, en p. 172.

40 Panes, op. cit. (nota 7), p. 110 de la primera parte. 
que se produjeron también otros en Galicia, aunque no detalla las poblaciones afectadas, y anotará también la renuncia al convento de San Mateo. Apuntará más causas pero su discurso parece bastante enigmático. El convento, nos dirá:

dos años despues se dexó por la falta que tenía de agua para el riego de la huerta, y sustento de la Comunidad, y otras causas e inconuinientes que al principio no se entendieron, y el tiempo las descubrio ${ }^{41}$.

La mención a lo que sucedería en Zalamea (Badajoz) -"casi lo mismo"- parece indicar el camino que debe explicar los hechos de San Mateo.

Efectivamente, por los mismos años, pero en la provincia de San José, los franciscanos descalzos renunciaban a consolidar la fundación conventual recientemente instituida en la población extremeña de Zalamea de la Serena. El inicio de la presencia franciscana se produciría hacia 1577 y en 1583 los frailes abandonaban el lugar. También en este caso contamos con dos fuentes cronísticas. La del citado Santa María y la de fray José de Santa Cruz que escribía la historia de la provincia de San Miguel de los franciscanos observantes que igualmente se extendía por territorio extremeño ${ }^{42}$. Ambos cronistas, aunque difieren en sus juicios, coinciden en la explicación de los hechos. Al parecer se estaba dilatando en exceso la obra conventual y no se estaba cumpliendo "con lo assentado de hazer el Conuento" 43 en los términos y con la puntualidad que los frailes precisaban.

El relato de Santa María tiene un tono más justificativo, mientras que la exposición de Santa Cruz es más crítica con la política de los descalzos, y de su relato merece la pena transcribir el juicio que le merecía la renuncia de los frailes de la provincia de San José, a pesar de que la villa les pedía paciencia y les aseguraba que haría lo posible por cumplir con lo acordado:

Con todo executaron su determinación; porque aunque la villa necesitaua de Religiosos; ellos no necesitauan de Conuentos, pues tenian con las dos Castillas, y Estremadura cogida buena parte de España ${ }^{44}$.

En cualquier caso, como vemos, el incumplimiento de los compromisos fundacionales se convertía nuevamente en un factor que conseguía dar al traste con un establecimiento religioso. La misma realidad estaría detrás de la deserción que se produjo en la localidad de Dos Hermanas (Sevilla), que vería cómo en muy poco tiempo se perdía el convento que se había establecido en sus términos. En este caso la falta de apoyo y la dejación de las responsabilidades asumidas de cara a la fundación vinieron de parte del señor temporal de la villa, que era quien había solicitado el establecimiento del conven-

\footnotetext{
41 SANTA MARÍA, op. cit. (nota 28), p. 528.

42 Santa Cruz, Fray J. de: Crónica de la Provincia Franciscana de San Miguel. Parte primera, Reproducción facsimilar de la edición de 1671. Introducción e Índices de H. Zamora Jambrina, Madrid, Editorial Cisneros, 1989, pp. 467-468. El relato de Santa Cruz se explica porque serían los observantes de esta provincia de San Miguel los que, una vez abandonada la fundación por los descalzos, ocuparían su lugar en 1584.

43 SANTA MARÍA, op. cit. (nota 28), p. 528

44 SANTA CRUZ, op. cit. (nota 42), p. 468.
} 
to a los franciscanos descalzos y con quien se habían establecido algunos pactos. Sin ellos, asegura el cronista, no se podía proceder a la fundación "en aquella Población tan corta" ${ }^{45}$. Y es que, ciertamente, muchas de las fundaciones realizadas, por la pobreza de las poblaciones y las escasas posibilidades de asegurar las limosnas precisas, no podían subsistir sin el apoyo de otras instancias. Este debió ser uno de estos casos. La fundación fue admitida por la provincia con estas precauciones en 1641 y pronto los religiosos se vieron obligados a hacer repetidos llamamientos al señor para que aportara la contribución que había comprometido y procediera también a dar comienzo a la fábrica del convento. Al parecer ni lo uno ni lo otro se ejecutaba y estaba claro la pequeña población tampoco podía hacerse cargo. En el Capítulo provincial de 1644 se decidía renunciar a todo y los frailes procederían a su retirada.

Imposibilidad y dificultades para asegurarse el mantenimiento y la supervivencia explican, como vemos, el desmantelamiento de algunas comunidades religiosas establecidas. También en este escenario se produjo el desenlace que terminó con la brevísima presencia de una comunidad de franciscanos descalzos que se instaló en Tabernas (Almería) en 1692. En este caso no se trataba de un convento sino de un Hospicio integrado por apenas cinco religiosos, que muy pronto vieron cómo era muy complicado su sostenimiento puesto que para garantizarlo debían estar mendigando diariamente tres religiosos en los lugares del entorno y además no tardaría tampoco en hacerse evidente la dificultad para fabricar un convento. En año y medio, las autoridades de la Provincia decidieron renunciar a proseguir su estancia en la localidad y dispusieron su abandono. El relato tiene un interés añadido, pues el cronista cuenta entonces cómo la población se amotinó para impedir que los frailes marcharan, cómo se prolongaría unos meses más su residencia ante las promesas de mayor apoyo, que resultaron infructuosas y cómo finalmente se retiraron de forma definitiva tras dos años y cuatro meses en Tabernas ${ }^{46}$.

Todos estos casos que venimos examinando nos sitúan ante situaciones de abandono de los establecimientos religiosos fundados y decisiones de desamparo tomadas por las autoridades de las órdenes religiosas. Eran, por tanto, las propias órdenes las que renunciaban ante las dificultades para subsistir y cabe pensar que no se encontró otra alternativa para la permanencia de aquellos asentamientos, como sí sucedió en otras ocasiones. Son innumerables los casos en los que los conventos originalmente fundados cambiaron su situación dentro de los contornos o los términos de la misma villa, pero no se produjeron abandonos ${ }^{47}$. Sobre todo en aquellos casos en los que la renuncia se produjo aduciendo razones de insalubridad del enclave elegido para el establecimiento conventual, como en Sollana, en Almenara o en Castalla, cuesta pensar que no se pudieran hallar otras fórmulas de solución que no pasaran por la retirada y es muy posible que a estas motivaciones expuestas haya que añadir otras de más difícil precisión sin

\footnotetext{
45 Jesús María, op. cit. (nota 12), pp. 707-708.

46 García Alcaraz, op. cit. (nota 9), pp. 387-391 de la segunda parte. También, con la misma fuente, explica A. Fermández Ortega el caso de Tabernas. Fernández OrtegA, A.: "La expansión de la orden descalza franciscana en el reino de Granada", en IV Curso de Verano. El franciscanismo en Andalucía, Córdoba, Asociación Hispánica de Estudios Franciscanos, 2000, pp. 259-274.

47 Por poner algún ejemplo, citaremos el de Villarreal (Castellón), donde los franciscanos descalzos tomarían posesión en 1577 en una ermita de Nuestra Señora de Gracia y por la poca sanidad del lugar y otras incomodidades pedirían a la villa que les cediera otra, con la advocación de Nuestra Señora del Rosario, a la que se trasladarían al año siguiente. PANES, op. cit. (nota 7), p. 102 de la primera parte.
} 
contar con otra documentación o información más detallada, aunque como hemos visto en los textos de J. de Castro, algunos cronistas sí trataron de justificar este proceder.

En cualquier caso, sí parece que se dieron más casos de conventos desamparados invocando lo insano del terreno. Panes lo afirma rotundo tras relatar el abandono del convento fundado en Sollana: "Y porque no ha sido solamente esta casa la que se ha dexado por poco sana..." ${ }^{48}$, si bien no aporta más detalle de en qué otros lugares se produjeron estas renuncias.

En otros casos, no obstante, sí sabemos que la operación que se produjo fue un traslado de convento de una localidad a otra, generalmente próxima. Así, el convento de franciscanos que habría sido fundado "en un sitio escabroso y descomodado que llaman Sueiro"49 en el siglo XIV se trasladaría a la vecina villa de Noya (La Coruña) en 1522, o el que se había levantado en 1458 en Cidamón (La Rioja) se trasladaría en 1535 a la vecina Santo Domingo de la Calzada, en este caso sería el resultado de la decisión que tomaron las autoridades provinciales para atender la petición procedente de esta última localidad de que los franciscanos fundaran convento en ella ${ }^{50}$. En ambos casos las localidades estaban muy cerca.

Igualmente hubo una presencia muy efímera-apenas de diez meses- de franciscanos descalzos en Ciudad Rodrigo (Salamanca). Una estancia fugaz que se produjo en el contexto de los debates que se produjeron en torno al mantenimiento o cierre de otro convento próximo de la misma orden, el de Sancti Spiritus de Valdárrago en los términos de Robledillo de Gata (Cáceres), que había sido fundado en 1556, en un paraje demasiado aislado, con otro convento de la misma orden en la misma villa de Robledillo y con problemas para garantizarse las limosnas y asegurar la subsistencia de sus frailes. Al parecer algunos religiosos eran partidarios de abandonar el convento, mientras que otros defendían que la solución podía pasar por trasladarlo a Ciudad Rodrigo. Esto es lo que se hizo en octubre de 1622, si bien la polémica en el seno de la provincia al respecto de esta decisión se avivó y pasados diez meses, los religiosos retornaban al cenobio de Sancti Spiritus. En 1643 el convento se abandonaría definitivamente y sus instalaciones fueron desmanteladas ${ }^{51}$.

Por lo demás, también en algunos otros casos las explicaciones sobre las razones del fin de la vida conventual están ausentes, aunque al menos podemos rescatar para la historia sus efímeras existencias, como el de un convento de franciscanos en la villa de Alhama de Granada que debió fundarse en tiempos de los Reyes Católicos y que posteriormente fue abandonado. El cronista, Alonso de Torres, no aporta mucho más, sólo que el final debió producirse con anterioridad a $1562^{52}$.

\footnotetext{
48 Ibídem, p. 36 de la primera parte.

49 Anónimo: Crónica de la Provincia Franciscana de Santiago, 1214-1614, Introducción de Manuel de Castro, Madrid, Archivo Ibero Americano, 1971.

50 Garay, M.: Compendio chronologico con nuevas adiciones a la Primera parte de la Crónica de la Santa Provincia de Burgos. Pamplona, 1742, pp. 119-124.

51 El relato de esta estancia tan breve en Ciudad Rodrigo y los avatares de la comunidad de Sancti Spiritus de Valdarrago se desarrollan con más detalle en la monografía de H. Amez, que también usa como fuente la crónica de Juan de Trinidad. Amez Prieto, H.: La Provincia de San Gabriel de la Descalcez franciscana extremeña. Arganda del Rey, Ediciones Guadalupe, 1999, pp. 445-450.

52 Torres, Fray A. de: Crónica de la Provincia franciscana de Granada, Reproducción de la edición del año 1683. Edición preparada por Rafael Mota Murillo. Madrid, Editorial Cisneros, 1983, p. 480, tomo I.
} 
Por último, también el azote de las guerras y los conflictos bélicos constituyó otro factor que llevaría al abandono de otros conventos ya instituidos. Sería el caso del cenobio levantado por los franciscanos en Salvatierra (Pontevedra), tan próximo a la frontera con Portugal. El convento fue fundado por los condes de Salvatierra hacia 1603, pero sería destruido en el contexto de las guerras con Portugal en $1641^{53}$. Este conflicto con Portugal también haría estragos en la existencia de los franciscanos descalzos de la provincia de San Gabriel que vieron cómo se perdían algunos conventos próximos a la frontera y que llevaban largo tiempo fundados, como los extremeños de Nuestra Señora de la Luz de Moncarche, el de Villanueva del Fresno, el de San Gabriel de Alconchel, el de Valverde de Leganés... Si bien es cierto que en algunos de estos casos los frailes retornarían y se reconstruirían los conventos, algunos se perdieron definitivamente ${ }^{54}$.

Como hemos podido ver, el proceso de expansión de las órdenes religiosas en la España Moderna presenta una dimensión hasta el momento poco explorada. Es la dimensión menos exitosa, la cara menos feliz, la de los intentos malogrados de fundación conventual, la de los conventos de vida breve, que se abandonaron o desmantelaron en poco tiempo, y aunque es imposible precisar con rigor la entidad de este fenómeno que nos ha ocupado y sistematizar su cronología, sí ha sido viable comenzar a apuntar algunas de sus tendencias. El caso de la provincia de San Pablo nos ha permitido vislumbrar que la magnitud numérica de las fundaciones frustradas respecto a la entidad conventual de la provincia fue bastante notable. Y todo parece indicar también que los problemas y las dificultades arreciaron durante el siglo XVII. Tiempos de crisis, y de conciencia de saturación conventual.

La paralización de operaciones fundacionales remite a un abanico razones que fue amplio y dispar. La negativa de las jerarquías episcopales a otorgar la licencia que era preceptiva frustraría algunas expectativas, la insuficiencia de recursos o la debilidad o incumplimiento de los compromisos finales de alguno de los actores que habrían tomado la iniciativa para el establecimiento conventual también acabó con otros o pudo ser razón de una vida efímera. Fueron muchos los movimientos fundacionales que se truncaron ante las oposiciones y las contrariedades que se suscitaron entre otras órdenes religiosas y/o otras instancias. La competencia, como sabemos, fue una constante. Pero también hemos podido agregar otro factor explicativo de especial interés, el que remite a una acción política de autorregulación por parte de las familias religiosas y nos sitúa ante conventos que las autoridades de la orden consideraron que no era factible o provechoso conservar o propuestas de fundación que esas mismas jerarquías estimaron que no convenía aceptar, decisiones y resoluciones políticas que nos deben obligar a introducir matices sobre alguna de las ideas que parecían asentadas en la historiografía sobre la compulsión fundacional y la expansión de los regulares en aquella España del Antiguo Régimen.

\footnotetext{
53 ANÓNIMO, op. cit. (nota 49), p. 286.

54 Pueden seguirse los casos mencionados en el trabajo de H. Amez Prieto, que remite también a las crónicas franciscanas consultadas. Amez Prieto, op. cit. (nota 51).
} 


\section{Relación de fundaciones frustradas y efímeras (*)}

\begin{tabular}{|c|c|c|c|}
\hline Localidad & $\begin{array}{l}\text { Convento } \\
\text { Orden }\end{array}$ & Fechas aproximadas & $\begin{array}{c}\text { Fundación } \\
\text { Frustrada (F) } \\
\text { Efímera (E) }\end{array}$ \\
\hline Honrubia & F.D & 1617 & $\mathrm{~F}$ \\
\hline Castillo de Garcimuñoz & F.D & 1617 & $\mathrm{~F}$ \\
\hline Huelma & F.D & 1670 & $\mathrm{~F}$ \\
\hline Quesada & F.D & $1670 \mathrm{y}$ antes & $\mathrm{F}$ \\
\hline Aracena & F.D & 1656 & $\mathrm{~F}$ \\
\hline Ciudad Rodrigo & F.D & Sin fecha & $\mathrm{F}$ \\
\hline Astorga & F.D & Sin fecha & $\mathrm{F}$ \\
\hline Rioseco & F.D & Sin fecha & F \\
\hline Fuente la Peña & F.D & Sin fecha & $\mathrm{F}$ \\
\hline Roa & F.D & Sin fecha & $\mathrm{F}$ \\
\hline Oviedo & F.D & Hacia 1650 & $\mathrm{~F}$ \\
\hline Burgos & F.D & Sin fecha & $\mathrm{F}$ \\
\hline Pedraza & F.D & Sin fecha & F \\
\hline La Puebla & F.D & Sin fecha & $\mathrm{F}$ \\
\hline Fermoselle & F.D & Sin fecha & $\mathrm{F}$ \\
\hline El Bierzo (cuatro villas sin concretar) & F.D & Sin fecha & $\mathrm{F}$ \\
\hline Tobarra & F.D & 1604 & $\mathrm{~F}$ \\
\hline Elche & F.OBS & 1520 & $\mathrm{~F}$ \\
\hline Bembibre & F.OBS & Sin fecha & $\mathrm{F}$ \\
\hline Mondoñedo & F.R & 1600 & $\mathrm{~F}$ \\
\hline Gijón & F.R & 1601 & $\mathrm{~F}$ \\
\hline Salvatierra & F.OBS & Sin fecha & F \\
\hline Puente Áreas & F.OBS & Sin fecha & $\mathrm{F}$ \\
\hline Sollana & F.D & $1562-1603$ & E \\
\hline Almenara & F.D & $1574-1585$ & $\mathrm{E}$ \\
\hline Castalla & F.D & $1575-1585$ & $\mathrm{E}$ \\
\hline Fonz & F.D & $1638-i ?$ & $\mathrm{E}$ \\
\hline Biar & F.OBS & $1572-1588$ & $\mathrm{E}$ \\
\hline Lliria & F.OBS & $1562-1571$ & $\mathrm{E}$ \\
\hline San Mateo & F.D & $1582-1584$ & $\mathrm{E}$ \\
\hline Zalamea de la Serena & F.D & $1577-1583$ & $\mathrm{E}$ \\
\hline Dos Hermanas & F.D & $1641-1644$ & $\mathrm{E}$ \\
\hline Tabernas & F.D & $1692-1695$ & $E$ \\
\hline Sueiro (trasladado a Noya) & F.OBS & XIV-1522 & E -Traslado \\
\hline Cidamón (tras. A Sto Domingo de la Calzada) & F.OBS & $1458-1535$ & E -Traslado \\
\hline Ciudad Rodrigo & F.D & $1622-1623$ & $\mathrm{E}$ \\
\hline Alhama de Granada & F.OBS & XV-Antes 1562 & $\mathrm{E}$ \\
\hline Salvatierra (Pontevedra) & F.OBS & $1603-1641$ & $\mathrm{E}$ \\
\hline
\end{tabular}

(*) Las fuentes cronísticas correspondientes a cada uno de los conventos se relacionan en el texto.

F.D - Franciscanos descalzos

F.OBS - Franciscanos Observantes

F.R - Franciscanos recoletos 